Цитирование: Бредер В.В., Базин И.С., Косырев В.Ю., Ледин Е.В. Практические рекомендации по лекарственному лечению билиарного рака. Злокачественные опухоли: Практические рекомендации RUSSCO \#3s2, 2021 (том 11). 26

\title{
ПРАКТИЧЕСКИЕ РЕКОМЕНДАЦИИ ПО ЛЕКАРСТВЕННОМУ ЛЕЧЕНИЮ БИЛИАРНОГО РАКА
}

Коллектив авторов: Бредер В.В., Базин И.С., Косырев В.Ю., Ледин Е.В.

Ключевые слова: рак билиарного тракта, внутрипеченочная холангиокарцинома, внепеченочная холангиокарцинома, опухоль Клацкина, рак желчного пузыря, химиотерапия, химиолучевая терапия, аблация, СА19-9

\section{1. КЛАССИФИКАЦИЯ И ОПРЕДЕЛЕНИЕ СТАДИИ}

Для стадирования применяется 8-ая редакция классификации по системе TNM Международного противоракового союза АJCC/UICC (uicc.org/resources/tnm), отдельная для внутри-и внепеченочных, желчных протоков, опухолей ворот печени и желчного пузыря.

\section{1. Стадирование рака желчного пузыря}

\section{T- первичная опухоль}

TX - недостаточно данных для оценки первичной опухоли;

Т0 - первичная опухоль не определяется;

Tis - рак in situ;

Т1 - опухоль прорастает в собственную пластинку или мышечный слой;

Т1а - опухоль прорастает в собственную пластинчатую оболочку;

T1b - опухоль прорастает в мышечный слой;

Т2 - опухоль проникает в перимускулярную соединительную ткань на брюшной стороне, без вовлечения серозы (висцеральной брюшины) или в перимышечную соединительную ткань на печеночной стороне без врастания в печень;

T2a - опухоль проникает в перимускулярную соединительную ткань на брюшной стороне, без вовлечения серозы (висцеральной брюшины);

Т2в - опухоль проникает в перимускулярную соединительную ткань на печеночной стороне, без врастания в печень;

Т3 - опухоль прорастает в серозу (висцеральную брюшину) и/или имеется прямая инвазия в печень и/или другие соседние органы и структуры (желудок, 12-перстную кишку, ободочная кишка, поджелудочная железа, сальник, внепеченочные желчные протоки);

T4 - инвазия опухоли в воротную вену или печеночную артерию, или инвазия двух и более органов и структур. 


\section{$\mathbf{N}$ - регионарные лимфатические узлы}

$\mathrm{NX}$ - недостаточно данных для оценки поражения лимфоузлов;

$\mathrm{NO}$ - нет признаков метастатического поражения регионарных лимфатических узлов;

N1 - поражение от одного до трех регионарных лимфатических узлов;

$\mathrm{N} 2$ - поражение четырех и более лимфатических узлов.

\section{М- отдаленные метастазы}

M0 - нет отдаленных метастазов;

Таблица 1. Группировка рака желчного пузыря по стадиям

\begin{tabular}{|l|l|l|l|}
\hline Стадия & T & N & M \\
\hline Стадия 0 & Tis & N0 & M0 \\
\hline Стадия I & T1 & N0 & M0 \\
\hline Стадия IIA & T2а & N0 & M0 \\
\hline Стадия IIB & T2в & N0 & M0 \\
\hline Стадия IIIA & T3 & N0 & M0 \\
\hline Стадия IIIB & T1-3 & N1 & M0 \\
\hline Стадия IVA & T4 & N0-1 & M0 \\
\hline Стадия IVB & Любая T & N2 & M0 \\
\cline { 2 - 4 } & Любая T & Любой N & M1 \\
\hline
\end{tabular}

\section{2. Стадирование рака внутрипеченочных желчных протоков.}

\section{Т - первичная опухоль}

Тх - недостаточно данных для оценки первичной опухоли,

Т0 - первичная опухоль не определяется,

Tis - рак in situ (внутрипротоковая опухоль);

Т1 - солитарная опухоль без инвазии сосудов, <5 см или >5 см,

Т1а - солитарная опухоль < 5 см без инвазии сосудов,

$\mathrm{T} 1 \mathrm{~b}-$ солитарная опухоль $>5$ см без инвазии сосудов,

Т2 - солитарная опухоль с внутрипеченочной инвазии сосудов или множественные опухолевые узлы в сочетании или без инвазии сосудов;

Т3 - опухоль, прорастающая висцеральную брюшину;

T4 - опухоль, вовлекающая местные структуры путем прямой инвазии.

\section{$\mathrm{N}$ регионарные лимфатические узлы}

$\mathrm{Nx}$ - недостаточно данных для оценки состояния регионарных лимфатических узлов,

$\mathrm{NO}$ - нет признаков метастатического поражения регионарных лимфатических узлов,

N1 - имеется поражение регионарных лимфатических узлов метастазами.

\section{М - отдаленные метастазы}

Мо - нет признаков отдаленных метастазов;

M1 - имеются отдаленные метастазы. 
Таблица 2. Группировка по стадиям рака внутрипеченочных желчных протоков

\begin{tabular}{|l|l|l|l|}
\hline Стадия & $\mathbf{T}$ & $\mathbf{N}$ & $\mathbf{M}$ \\
\hline 0 & Tis & 0 & 0 \\
\hline $\mathrm{IA}$ & $1 \mathrm{a}$ & 0 & 0 \\
\hline $\mathrm{IB}$ & 1в & & \\
\hline $\mathrm{II}$ & 2 & 0 & 0 \\
\hline $\mathrm{IIIA}$ & 3 & 0 & 0 \\
\hline $\mathrm{IIIB}$ & 4 & 0 & 0 \\
\hline $\mathrm{IV}$ & Любая & Любая & 1 \\
\hline
\end{tabular}

\section{3. Стадирование рака внепеченочных желчных протоков (в области ворот печени)}

\section{T - первичная опухоль}

TX - недостаточно данных для оценки первичной опухоли;

Т0 - первичная опухоль не определяется;

Tis - рак in situ (высокая степень дисплазии);

T1 - опухоль, ограниченная желчным протоком, с расширением до мышечного слоя или волокнистой (фиброзной) ткани;

Т2 - опухоль проникает за стенку желчного протока в окружающую жировую ткань или в соседнюю печеночную паренхиму:

Т2а - опухоль прорастает за пределы стенки протока с инвазией в окружающую жировую ткань;

Т2b - опухоль прорастает в прилежащую паренхиму печени;

Т3 - опухоль прорастает в ветви воротной вены или печеночной артерии с одной стороны;

T4 - опухоль прорастает в главный ствол воротной вены или ее ветви с обеих сторон или инвазия общей печеночной артерии; или распространение опухоли на протоки 2-го порядка с обеих сторон; поражение протоков 2-го порядка с одной стороны с инвазией контралатеральной ветви воротной вены или вовлечением печеночной артерии.

\section{N - регионарные лимфатические узлы}

$\mathrm{NX}$ - недостаточно данных для оценки поражения лимфоузлов;

$\mathrm{NO}$ - нет признаков метастатического поражения регионарных лимфатических узлов;

N1 - 1-3 пораженных метастазами лимфатических узла, поражение лимфоузлов вдоль пузырного протока, общего желчного протока, печеночной артерии, задней панкреатодуоденальной и/или воротной вены;

N2 - $\geq 4$ пораженных метастазами лимфатических узлов из участков, описанных для N1.

\section{М - отдаленные метастазы}

МО - нет отдаленных метастазов;

М1 - есть отдаленные метастазы. 
Таблица 3. Группировка по стадиям рака внепеченочных желчных протоков (в области ворот печени)

\begin{tabular}{|l|l|l|l|}
\hline Стадия 0 & Tis & N0 & M0 \\
\hline Стадия I & T1 & N0 & M0 \\
\hline Стадия II & T2a-b & N0 & M0 \\
\hline Стадия IIIA & T3 & N0 & M0 \\
\hline Стадия IIIB & T4 & N0 & M0 \\
\hline Стадия IIIC & Любая T & N1 & M0 \\
\hline Стадия IVA & Любая T & N2 & M0 \\
\hline Стадия IVB & Любая T & Любая N & M1 \\
\hline
\end{tabular}

Модифицированная система стадирования Bismuth-Corlette классифицирует опухоли проксимальных желчных протоков на 4 типа на основании степени вовлечения желчных протоков (табл. 4).

Таблица 4. Классификация Bismuth-Corlette (для рака проксимальных желчных протоков)

\begin{tabular}{|l|l|}
\hline Tип I & Поражение общего печеночного протока \\
\hline Тип II & Поражение слияния печеночных протоков \\
\hline Тип IIIA & Поражение правого печеночного протока \\
\hline Tип IIIB & Поражение левого печеночного протока \\
\hline Tип IV & Поражение обоих печеночных протоков \\
\hline
\end{tabular}

\section{4. Стадирование рака внепеченочных желчных протоков (дистальные - ниже впадения пузырного протока)}

\section{T - первичная опухоль}

TX - недостаточно данных для оценки первичной опухоли;

Т0 - первичная опухоль не определяется;

Tis - рак in situ (высокая степень дисплазии);

T1 - опухоль проникает в стенку протока на глубину менее 5 мм;

Т2 - опухоль проникает в стенку протока на глубину 5-12 мм;

Т3 - опухоль проникает в стенку протока на глубину более 12 мм;

Т4 - инвазия опухоли в чревный ствол, верхнюю брыжеечную артерию и/или общую печеночную.

\section{N - регионарные лимфатические узлы}

$\mathrm{NX}$ - недостаточно данных для оценки поражения лимфоузлов;

$\mathrm{NO}$ - нет признаков метастатического поражения регионарных лимфатических узлов;

N1- 1-3 пораженных метастазами лимфатических узла;

$\mathrm{N} 2-\geq 4$ пораженных метастазами лимфатических узлов. 
М - отдаленные метастазы

Мо - нет отдаленных метастазов;

M1 - есть отдаленные метастазы.

Таблица 5. Группировка по стадиям рака внепеченочных желчных протоков (дистальных)

\begin{tabular}{|c|c|c|c|}
\hline Стадия 0 & Tis & No & MO \\
\hline Стадия I & $\mathrm{T} 1$ & No & MO \\
\hline \multirow[t]{2}{*}{ Стадия IIA } & $\mathrm{T} 1$ & $\mathrm{~N} 1$ & MO \\
\hline & $\mathrm{T} 2$ & NO & MO \\
\hline \multirow[t]{3}{*}{ Стадия IIB } & $\mathrm{T} 2$ & $\mathrm{~N} 1$ & MO \\
\hline & T3 & No & MO \\
\hline & T3 & $\mathrm{N} 1$ & MO \\
\hline \multirow[t]{3}{*}{ Стадия IIIA } & $\mathrm{T} 1$ & N2 & MO \\
\hline & $\mathrm{T} 2$ & $\mathrm{~N} 2$ & MO \\
\hline & T3 & N2 & MO \\
\hline \multirow[t]{3}{*}{ Стадия IIIB } & $\mathrm{T} 4$ & NO & MO \\
\hline & T4 & N1 & Mo \\
\hline & $\mathrm{T} 4$ & N2 & MO \\
\hline Стадия IV & Любая Т & Любая N & M1 \\
\hline
\end{tabular}

\section{5. Анатомическая классификация}

Рак билиарного тракта - это группа опухолей, развивающихся из эпителия внутри-и внепеченочных желчных протоков (холангиокарциномы), а также желчного пузыря. Термин «холангиокарцинома» подразумевает три типа опухолей с различными факторами риска, свойствами и лечебными подходами - это внутри-и внепеченочные опухоли, а также поражение желчныхпротоков ворот печени, относящееся к опухолям внепеченочной локализации (опухоль Клацкина). В связи со сложностью диагностики данного типа опухолей, особенностями морфологических свойств, сбора и оценки эпидемиологических данных, точная статистика как по истинной распространенности заболевания, так и по распределению опухолей в пределах билиарного тракта отсутствует или сильно разнится. Считается, что на опухоли билиарного тракта приходится около $3 \%$ всех опухолей ЖКТ. Внутрипеченочные холангиокарциномы составляют около $10 \%$ случаев первичного рака печени, на опухоль Клацкина приходится 50\% случаев, на опухоли дистальной локализации - $40 \%$.

\section{6. Гистологическая классификация}

Более $90 \%$ опухолей желчных путей - эпителиальные аденокарциномы. Встречаются также плеоморфные, гигантоклеточные, аденосквамозные и коллоидные карциномы. Другие типы, такие как плоскоклеточный, мелкоклеточный, саркомы и лимфомы встречаются 
крайне редко (менее $5 \%$ случаев). По морфологическим свойствам аденокарциномы желчных путей разделены на три типа:

- склерозирующий (скиррозный) - представляет собой тип опухоли с высоким уровнем десмопластической реакции, часто манифестирующий диффузным утолщением протоков без формирования очерченной опухолевой массы; чаще развивается во внепеченочных желчных протоках, характеризуется сложностью верификации и низкой резектабельностью;

- нодулярный - чаще формируется в виде узлового циркулярного образования, суживающего проток; характеризуется высокими инвазивными свойствами и низкой резектабельностью;

- папиллярный (полипоидный) - представляет собой высокодифференцированную аденокарциному в виде полипоидного образования в просвете желчного протока, приводящего к билиарной обструкции, с минимальной инвазией и отсутствием десмопластической реакции; данный тип опухоли характеризуется ранней манифестацией и высокой резектабельностью.

Нередко при холангиокарциномах происходит формирование сателлитов и их диссеминация по желчным протокам. Поражение регионарных лимфатических узлов и периневральная инвазия чаще встречаются при опухолях Клацкина и дистальныхжелчных путей.

По степени злокачественности опухоли билиарного тракта вне зависимости от анатомической классификации подразделяются на:

Gx - недостаточно данных для оценки;

G1 - хорошо дифференцированная;

G2 - умеренно дифференцированная;

G3 - низкодифференцированная.

\section{2. ДИАГНОСТИКА}

Основой диагноза билиарного рака является морфологическое исследование. Биопсия обязательна для подтверждения диагноза в случае отказа от оперативного вмешательства и планировании ЛТ или XТ, а также в случаях сомнительной природы стриктур (например, хирургические вмешательства на протоках в анамнезе, первичный склерозирующийхолангит, камни желчных протоков и т. д.). Морфологическая верификация не обязательна при планируемом хирургическом лечении. Решение о выполнении биопсии или обоснованном отказе от ее выполнения должно приниматься на мультидисциплинарном онкологическом консилиуме.

\section{1. Обследование}

- Сбор жалоб и анамнеза.

- Врачебный осмотр, определение общего состояния по ECOG, общеклиническое обследование. 
- Лабораторная диагностика (общий и биохимический анализы крови, определение онкомаркеров СА19-9, РЭА, АФП (для внутрипеченочного поражения); следует учитывать, что уровень СА19-9 повышается при билиарной обструкции, гепатитах, холелитиазе, муковисцидозе и др.

- МРТ с контрастированием и МР-холангиопанкреатографией (МРХПГ).

- КТ грудной клетки, брюшной полости и малого таза с в/в контрастированием.

- Диагностическая лапароскопия; в связи с высокой частотой перитонеального диссеминирования данный метод позволяет отказаться от неоправданной лапаротомии у трети больных, у которых по результатам МРТ/КТ/ПЭТ-КТ процесс представляется резектабельным.

- УзИ обладает высокой чувствительностью в выявлении расширения желчных протоков и определения уровня обструкции.

- Эндо-УзИ и эндоскопическая ретроградная холангиопанкреатография (ЭРХПГ) - по показаниям; дополнительно к визуализации патологической зоны позволяют выполнить тонкоигольную биопсию или браш-биопсию для морфологической верификации опухоли; при недостаточной информативности ЭРХПГ возможно выполнение холангиоскопии (для прямой визуализации желчного протока) и биопсии. В случаях, когда опухолевое поражение недоступно эндоскопически, рекомендуется выполнение чрескожной чреспеченочной холангиографии (ччХГ).

- ПЭТ/КТ - по показаниям. Не является адекватной заменой диагностической лапароскопии.

\section{2. Особенности диагностики рака желчных путей}

Диагностический поиск с подозрением на рак желчных путей следует начинать при билиарной обструкции (например, желтухе, изменении печеночных показателей холестатических свойств, расширении протоков при инструментальных исследованиях) в отсутствие ее альтернативного объяснения, например, холедохолитиаза или патологического образования головки поджелудочной железы. При выявлении бессимптомных узловых образований в печени в первую очередь следует исключить метастазы опухолей других органов, а также доброкачественные и паразитарные образования печени. Холангиокарциному следует исключать у пациентов с изолированными образованиями печени, выявленными при инструментальных методах при нормальном уровне АФП, РЭА и СА19-9 (рис. 1). Поскольку к факторам риска развития внутрипеченочной холангиокарциномы, помимо вирусных гепатитов В и С, первичного склерозирующего холангита, относится цирроз печени, образования, выявленные на фоне цирроза печени, следует дифференцировать между печеночно-клеточным раком, холангиокарциномой и холангиоцеллюлярным раком. 


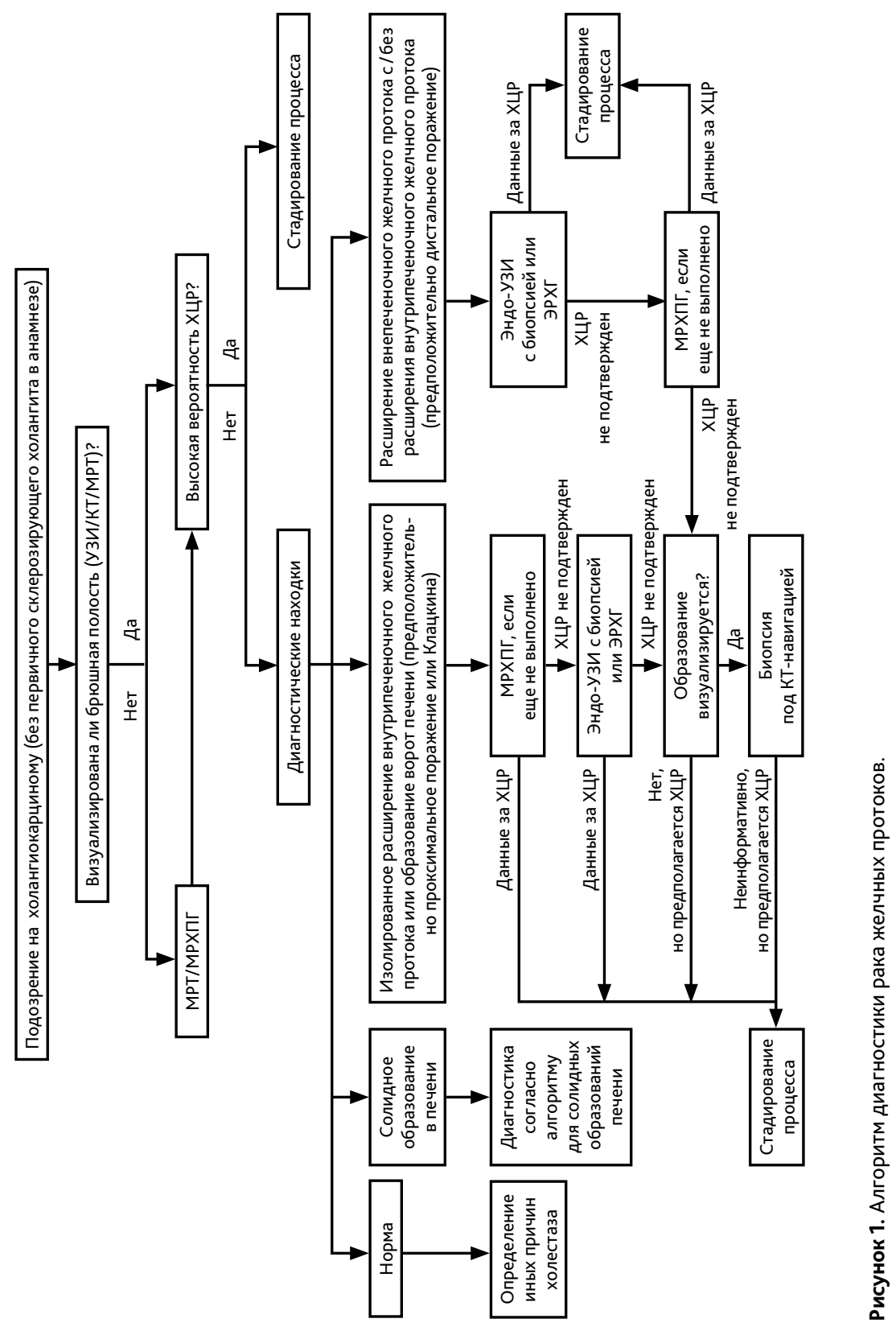




\section{3. Особенности диагностики рака желчного пузыря}

Пациенты с ранним раком желчного пузыря в большинстве случаев имеют неспецифические симптомы, схожие с холециститом. Почти в половине случаев диагноз устанавливается случайно в ходе/после холецистэктомии, выполняемой по поводу доброкачественного заболевания. При подозрении на рак желчного пузыря и планируемом хирургическом лечении предоперационое обследование должно включать в себя МРХПГ для дифференцировки злокачественного и доброкачественного поражения желчного пузыря, а также КТ с в/в контрастированием для определения распространенности заболевания.

К факторам риска рака желчного пузыря относятся желчнокаменная болезнь (риск повышается по мере увеличения размера камней и длительности холелитиаза), полипы желчного пузыря более 1 см в диаметре, кальцинация органа, первичный склерозирующий холангит. К пациентам, имеющим факторы риска развития рака желчного пузыря, требуется дифференцированный подход. Очаговые изменения желчного пузыря размером более 20 мм следует исходно рассматривать как злокачественные, обследовать и лечить по программе лечения рака желчного пузыря. Регулярное выполнение УЗИ рекомендовано при полипах желчного пузыря размером 6-9 мм каждые 6 мес. в течение 1 года, далее ежегодно с хирургическим лечением в случае увеличения их размеров (до 10-20 мм).

\section{3. ЛЕЧЕНИЕ}

\section{1. Локализованные формы}

Операция остается единственным методом, способным излечить пациента с опухолью билиарного тракта. Цель хирургического лечения - достижение RO-резекции, что ассоциируется с наибольшей выживаемостью.

\subsection{1. Рак желчного пузыря}

При раке желчного пузыря резектабельны от 10 до $30 \%$ опухолей. При выявлении потенциально резектабельной опухоли показано выполнение резекции en bloc желчного пузыря с прилежащей паренхимой печени (анатомическая или неанатомическая резекция) и регионарных лимфоузлов или внепеченочных желчных протоков. При случайном выявлении рака желчного пузыря во время холецистэктомии или при T1b-стадии или большем поражении по результатам гистологического исследования рекомендуется выполнение повторной операции. Частота RO-резекций во время повторной операции вариабельна вследствие дополнительных находок в ходе релапаротомии.

\subsection{2. Опухоль Клацкина}

Хирургические подходы определяются на основании стадирования по Bismuth-Corlette (табл. 4) и предполагают выполнение различных уровней резекции печени. Основными прогностическими факторами являются край резекции, наличие лимфоваскулярной инвазии и метастазов в лимфатических узлах. 


\subsection{3. Внутрипеченочная холангиокарцинома}

Операцией выбора является резекция печени, цель которой-достижение негативных краев, что ассоциируется с лучшей выживаемостью. Поражение регионарных лимфатических узлов является важнейшим прогностическим фактором. Другими прогностическими факторами являются размер первичной опухоли, степень дифференцировки, наличие сосудистой или периневральной инвазии, опухолевых сателлитов. Послеоперационная 5-летняя выживаемость варьирует от 20 до 43\%. При внутрипеченочной холангиокарциноме не выполняется трансплантация печени из-за частого раннего прогрессирования.

\subsection{3. Внепеченочная холангиокарцинома}

Как правило, требуется выполнение резекции головки поджелудочной железы и лимфодиссекции, т. е. выполнение стандартной панкреатодуоденальной резекции. Основными прогностическими факторами являются поражение лимфатических узлов (N) и глубина инвазии опухоли (Т). 5-летняя выживаемость при интактных лимфатических узлах составляет от 54-62\%, при пораженных лимфатических узлах около $20 \%$. Для внутри-и внепеченочной холангиокарциномы повышенный уровень СА19-9 связан с неблагоприятным прогнозом.

\subsection{4. Адъювантная терапия}

На основании единственного положительного исследования III фазы всем пациентам при отсутствии противопоказаний к ХТ рекомендовано назначение в адъювантном режиме капецитабина (6 мес.), применение которого улучшает показатели выживаемости для всех групп больных (табл. 7).

На основании ряда исследований II фазы пациентам с низкодифференцированными опухолями и/или множественным пораженнем лимфатических узлов может применяться полихимиотерапия (гемцитабин +цисплатин, гемцитабин +капецитабин) (табл. 7).

Тактика лечения пациентов с положительными краями резекции (R1/R2) определяется индивидуально. Возможными опциями являются выполнение ререзекции, системная XT (согласно принципам лечения больных с метастатическим процессом) и/или ХлТ с фторпиримидинами. Для пациентов с запланированной ХЛТ в сочетании с адъювантной ХТ оптимальная последовательность данных методик точно не определена. Однако, предпочтительным является начало лечения с четырех месяцев системной ХT (капецитабин или гемцитабин +цисплатин/капецитабин) с последующей ХлТ, что позволяет избежать ненужной лт у пациентов с ранним отдаленным метастазированием.

\section{2. Местнораспространенный нерезектабельный процесс}

Лечение большинства пациентов с нерезектабельным местно-распространенным процессом является паллиативным, а результаты лечения и прогнозы мало отличаются от таковых при диссеминированном процессе и, как правило, обусловлены быстро прогрессирующей билиарной обструкцией. Задачами паллиативной терапии являются облегчение соответствующих симптомов и улучшение качества жизни. Предоперационная XT, в том 
числе молекулярно-направленная, оправдана для попытки перевода опухоли из нерезектабельного состояния в резектабельное. В данном случае через 4-6 месяцев терапии проводится повторная оценка резектабельности с принятием решения о хирургическом этапе лечения. Поскольку существующая системная ХT билиарного рака редко приводит к выраженному уменьшению размеров первичной опухоли, вероятность перевода первично не резектабельного процесса в резектабельный невысока.

\subsection{1. Внутрипеченочный местнораспространенный нерезектабельный билиарный рак}

При исходной нерезектабельности локализованного поражения или после завершения системной ХТ (гемцитабин +цисплатин/оксалиплатин или гемцитабин +капецитабин, молекулярно-направленная терапия) (табл. 7) может проводиться конформная лТ совместно с фторпиримидинами. Альтернативной опцией является проведение стереотаксической ЛТ.

Паллиативный эффект также может достигаться при трансартериальной химио (радио) эмболизации опухоли, радиочастотной или микроволновой аблации, однако преимущества данных методик перед ХЛТ не доказаны.

\subsection{2. Внепеченочный местнораспространеный нерезектабельный билиарный рак}

При внепеченочном билиарном раке возможно проведение системной ХT (гемцитабин +цисплатин/оксалиплатин или гемцитабин +капецитабин, молекулярно-направленная терапия) (табл. 7) со стереотаксической прецизионной конформной ХЛТ с фторпиримидинами. При желтухе, обусловленной обструкцией, ФДТ совместно со стентированием и/или дренированием имеет преимущество перед стентированием и/или дренированием в самостоятельном варианте, в том числе по показателям выживаемости и качеству жизни (рис. 2).

\section{3. Метастатический процесс}

Пациентам с неоперабельным или метастатическим процессом, осложненным желтухой, необходимо обеспечить желчеотток, что улучшает качество жизни больного и создает условия для проведения ХТ. При нарушении желчеотведения более чем в $25 \%$ случаев ХТ осложняется холангитом, чаще после реконструкции/дренирования/стентирования желчевыводящих путей. Лечение обострений холангита заключается в ранней антибактериальной терапии (сучетом антибиотикограммы) при обеспечении адекватного оттока желчи.

Гипербилирубинемия >2-3 ВГН, повышение уровня трансаминаз более чем в 5-8 раз, признаки стойкого нарушения белково-синтетической функции печени (альбумин плазмы <30г/л), острый холангит являются только относительными противопоказания к ХТ. При гипербилирубинемии предпочтительнее применение схем без гемцитабина, например фторурацил (+кальция фолинат) в монорежиме или в сочетании с оксалиплатином. В случаях заболевания на фоне цирроза проведение XТ сопряжено с высоким риском тяжелых осложнений. 


\subsection{1. Химиотерапия I линии}

Комбинация гемцитабина с цисплатином является стандартной схемой лечения в первой линии терапии нерезектабельного, рецидивирующего или метастатического рака желчевыводящих путей и обеспечивает медиану продолжительности жизни 11,7 мес. при сравнении с 8,1 мес. при применении гемцитабина в монорежиме (табл. 7). Пациенты получают данное преимущество вне зависимости от возраста (моложе или старше 65 лет), локализации первичного очага (внутри-или внепеченочные желчные протоки, желчный пузырь), распространенности заболевания (местнораспространенный процесс или генерализованное заболевание), предшествующей терапии (хирургическое лечение или стентирование). Однако, пациенты с функциональным статусом ECOG 2 балла лучше переносят монотерапию гемцитабином или фторпиримидинами. Опционально у больных с нарушением функции почек (расчетный клиренс креатинина <50 мл/мин.) может назначаться комбинация GemOx (табл. 7).

Комбинация гемцитабина и капецитабина является эффективной и хорошо переносимой опцией, о чем свидетельствует ряд иследований II фазы.

Монотерапия капецитабином, рекомендованная для лечения ослабленных пациентов, менее эффективна при холангиокарциноме, чем при раке желчного пузыря.

Оптимальная продолжительность первой линии терапии составляет 4-6 циклов с возможностью пролонгации лечения (при достижении и нарастании объективного ответа) либо до прогрессирования заболевания или развития выраженной клинически значимой токсичности.

\subsection{2. Химиотерапия II и последующих линий}

Оптимальная схема второй линии терапии не определена ввиду отсутствия сравнительных проспективных исследований. Преимуществом в отношении показателей выживаемости обладает молекулярно-направленная терапия, назначенная на основании дополнительного ИГХ и/или генетического исследований, включая комплексное геномное профилирование.

\subsubsection{1. Молекулярно-направленная терапия}

Опухоли билиарного тракта нередко имеют молекулярно-генетические изменения (табл. 6), которые являются потенциальными мишенями для специфических ингибиторов, многие из которых в настоящее время доступны (табл. 7). Необходимо понимать, что выявленная потенциально таргетируемая мутация не гарантирует получения пользы от лечения, направленного на данный механизм.

Эффективность молекулярно-направленной терапии в первой линии не изучена, терапевтические подходы рекомендованы к применению в качестве второй и последующих линий терапии. В отсутствие данных о потенциальных прогностических маркерах при прогрессировании на первой-второй линиях терапии может быть рекомендован мультикиназный ингибитор регорафениб.

Помимо редких альтераций, представленных в табл. 6, другим предиктивным биомаркером, определяющим ответ на иммунотерапию в отсутствие MSI-H является экспрессия 
PD-L1. В исследовании II фазы у пациентов с экспрессией PD-L1 > 1\% отмечался высокий уровень ответов при использовании ниволумаба, некоторые из которых сохранялись на протяжении длительного времени.

Таблица 6. Частота таргетируемых онкогенных изменений при билиарном раке

\begin{tabular}{|l|l|l|l|}
\hline Изменения & Внутрипеченочная & Внепеченочная & Желчный пузырь \\
\hline \% BRAF V600E & 5 & 3 & 1 \\
\hline$\%$ HER2 & $3-4$ & 11 & $16-20$ \\
\hline$\%$ MSI-H/dMMR & $1-10$ & $1-5$ & $1-5$ \\
\hline$\%$ NTRK & $<1$ & $<1$ & $<1$ \\
\hline$\%$ PD-L1 > 1\% & $28-43$ & & \\
\hline
\end{tabular}

В РФ пока недоступна таргетная терапия, эффективная при часто (до $10 \%$ случаев) встречаемых при внутрипеченочной холангиокарциноме транслокации FGFR2 и IDH1/2, транслокации RET (1-2\%).

\subsubsection{2. Цитостатическая терапия}

На основании единственного проспективного исследования III фазы большинству пациентов с прогрессированием на фоне терапии гемцитабином и цисплатином в качестве второй линии рекомендовано назначение оксалиплатина с фторурацилом (FOLFOX) (табл. 7), что проводит к статистически значимому увеличению показателей выживаемости в сравнении с плацебо.

В качестве терапии второй линии могут применяться также фторпиримидины в монорежиме, комбинация оксалиплатина с капецитабином или иринотекана с фторурацилом. Считается, что максимальное преимущество от второй линии ХТ получают пациенты с хорошим функциональным статусом (ECOG 0-1 балл), чувствительностью опухоли к первой линии XT, с периодом без прогрессирования более 6 мес. и относительно низким уровнем СА19-9 (<400 ед./мл). При длительном периоде (более 6 мес.) без прогрессирования после эффективной первой линии лечения возможно повторное использование гемцитабина с препаратом платины.

Таблица 7. Рекомендуемые режимы лекарственной терапии билиарного рака

\begin{tabular}{|c|c|}
\hline Название режима & Схема лечения \\
\hline Гемцитабин & Гемцитабин 1000 мг/м² в/в в 1-й, 8-й и 15-й дни каждые 28 дней \\
\hline Фторурацил+ кальция фолинат & 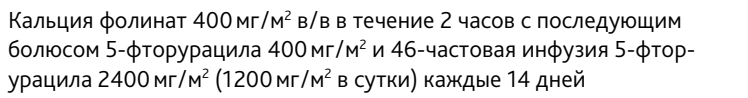 \\
\hline Капецитабин & $\begin{array}{l}\text { Капецитабин по } 1250 \text { мг/м²×2 раза в день внутрь в 1-й-14-й дни каждые } \\
21 \text { день }\end{array}$ \\
\hline
\end{tabular}




\begin{tabular}{|c|c|}
\hline Название режима & Схема лечения \\
\hline GemCis & $\begin{array}{l}\text { Гемцитабин } 1000 \text { мг/м² в/в в 1-й и 8-й дни + цисплатин } 25 \text { мг/м² в/в в 1-й } \\
\text { и 8-й дни каждые } 21 \text { день }\end{array}$ \\
\hline GemOx & $\begin{array}{l}\text { Гемцитабин } 1000 \text { мг/м² в/в в 1-й и 8-й дни + оксалиплатин } \\
100 \text { мг/м² в/в в 1-й и 8-й дни каждые } 21 \text { день }\end{array}$ \\
\hline GemCap & 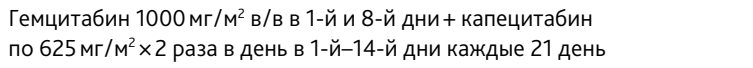 \\
\hline CapOx & $\begin{array}{l}\text { Капецитабин по } 1000 \text { мг/м²×2 раза в день в 1-й-14-й дни + оксали- } \\
\text { платин } 130 \text { мг/м² в/в 2-часовая инфузия в 1-й день каждые } 21 \text { день }\end{array}$ \\
\hline FOLFOX & $\begin{array}{l}\text { Оксалиплатин } 85 \text { мг/м² в/в } 120 \text { мин. в 1-й день, кальция фолинат } \\
400 \text { мг/м² в/в } 120 \text { мин., 5-фторурацил } 400 \text { мг/м² в/в болюс, 5-фтор- } \\
\text { урацил } 2400 \text { мг/м² в/в инфузия в течение } 46 \text { часов (1200 мг/м² в сутки) } \\
\text { каждые } 14 \text { дней }\end{array}$ \\
\hline FOLFIRI & $\begin{array}{l}\text { Иринотекан } 180 \text { мг/м² в/в } 90 \text { мин. в 1-й день, кальция фолинат } \\
400 \text { мг/м² в/в } 120 \text { мин., 5-фторурацил } 400 \text { мг/м² в/в болюс, 5-фтор- } \\
\text { урацил } 2400 \text { мг/м² в/в инфузия в течение } 46 \text { часов (1200 мг/м² в сутки) } \\
\text { каждые } 14 \text { дней }\end{array}$ \\
\hline $\begin{array}{l}\text { Пембролизумаб } \\
\text { (только для MSI-H/dMMR } \\
\text { опухолей) }\end{array}$ & $\begin{array}{l}\text { Пембролизумаб } 200 \text { мг в/в 30-минутная инфузия каждые } 21 \text { день } \\
\text { или } 400 \text { мг в/в капельно каждые } 42 \text { дня }\end{array}$ \\
\hline $\begin{array}{l}\text { Ниволумаб' } \\
\text { (только при PD-L1> 1\%) }\end{array}$ & $\begin{array}{l}240 \text { мг в/в 30-минутная инфузия каждые } 14 \text { дней или } 480 \text { мг в/в каждые } \\
28 \text { дней }\end{array}$ \\
\hline $\begin{array}{l}\text { BRAF + МЕК-ингибитор }{ }^{1} \\
\text { (только при мутации } \\
\text { BRAF V600E) }\end{array}$ & $\begin{array}{l}\text { Вемурафениб } 960 \text { мг внутрь } 2 \text { раза в день ежедневно + кобиметиниб } \\
60 \text { мг в сутки } 21 \text { день приема, } 7 \text { дней перерыв } \\
\text { Дабрафениб } 150 \text { мг внутрь × } 2 \text { раза в сутки ежедневно + траметиниб } 2 \text { мг } \\
\text { внутрь × } 1 \text { раз в сутки ежедневно, длительно }\end{array}$ \\
\hline Регорафениб & $\begin{array}{l}\text { Регорафениб } 160 \text { мг внутрь ежедневно 1-21 день каждого 28-дневного } \\
\text { цикла }\end{array}$ \\
\hline $\begin{array}{l}\text { Трастузумаб + пертузумаб }{ }^{1} \\
\text { (только при гиперэкспресии } \\
\text { или амплификации HER2) }\end{array}$ & $\begin{array}{l}\text { Трастузума6 } 8 \text { мг/кг в/в-нагрузочная доза в первый день первого } \\
\text { цикла, затем } 6 \text { мг/кг в/в-каждые } 21 \text { день, пертузума6- } 840 \text { мг } \\
\text { в/в нагрузочная доза в первый день первого цикла, затем } 420 \text { мг в/в- } \\
\text { каждые } 21 \text { день }\end{array}$ \\
\hline $\begin{array}{l}\text { NTRK-ингибиторы² } \\
\text { (только при NTRK-сшивке) }\end{array}$ & $\begin{array}{l}\text { Ларотректиниб } 100 \text { мг внутрь } 22 \text { раза в сутки ежедневно } \\
\text { Энтректиниб²600 мг внутрь ежедневно }\end{array}$ \\
\hline
\end{tabular}

1 Режим/nрепарат зарегистрирован в РФ, но не входит в клинические рекомендации, одобренные МинздравомРФ.

2 Препарат не зарегистрирован в РФ, но доступен по программе расширенного доступа и имеет доказанную эффективность.

Рекомендуемый алгоритм лечения билиарного рака в зависимости от степени распространенности представлен на рис. 2.

\section{4. Билиарная гипертензия}

Тактика отведения желчи у онкологических больных с механической желтухой опухолевой этиологии учитывает перспективы противоопухолевого лечения, ожидаемую 
продолжительность жизни пациента, локализацию и распространенность блока желчеоттока и степень нарушения функции печени. С учетом возможности внутрипротокового лечения опухолей (ФДТ, брахитерапия) и частой необходимости длительного доступа к желчным протокам купирование желчной гипертензии, по сути, является первым этапом для последующих диагностических и лечебных процедур. При определении показаний к желчеотведению необходимо соотносить риски вмешательства и предполагаемую клиническую пользу.

В большинстве случаев адекватным методом желчной декомпрессии является выполнение чрескожной чреспеченочной холангиостомии (одно/двухсторонней в зависимости от уровня блока и степени разобщения внутрипеченочных протоков) либо, при высоком риске развития тяжелых осложнений, эндоскопическая транспапиллярная установка съемного пластикового стента.

Имплантация саморасширяющихся металлических стентов в область опухолевой стриктуры оправдана, когда нет сомнений в диагнозе, отсутствуют перспективы противоопухолевого лечения и ожидаемая продолжительность жизни больного не превышает 3 мес. Однако, в зависимости от протяженности стриктуры и ее локализации, вопрос установки саморасширяющегося металлического стента может обсуждаться и при иных клинических состояниях.

\section{4. НАБЛЮДЕНИЕ}

Целью активного наблюдения является выявление раннего местного прогрессирования, предполагающее возможность применения локальных методов лечения. Известно, что до $65 \%$ рецидивов заболевания случаются в первые 2 года наблюдения и лишь $5 \%$ рецидивов диагностируются спустя 3 года. Эти данные подтверждают целесообразность активного наблюдения: КТ органов грудной клетки, брюшной полости и малого таза с в/в контрастированием, онкомаркеры (если были повышены до операции) каждые 6 мес. в первые 2 года, далее - ежегодно в течение 3 лет; при невозможности выполнения КТ применение УзИ и рентгенографии. 


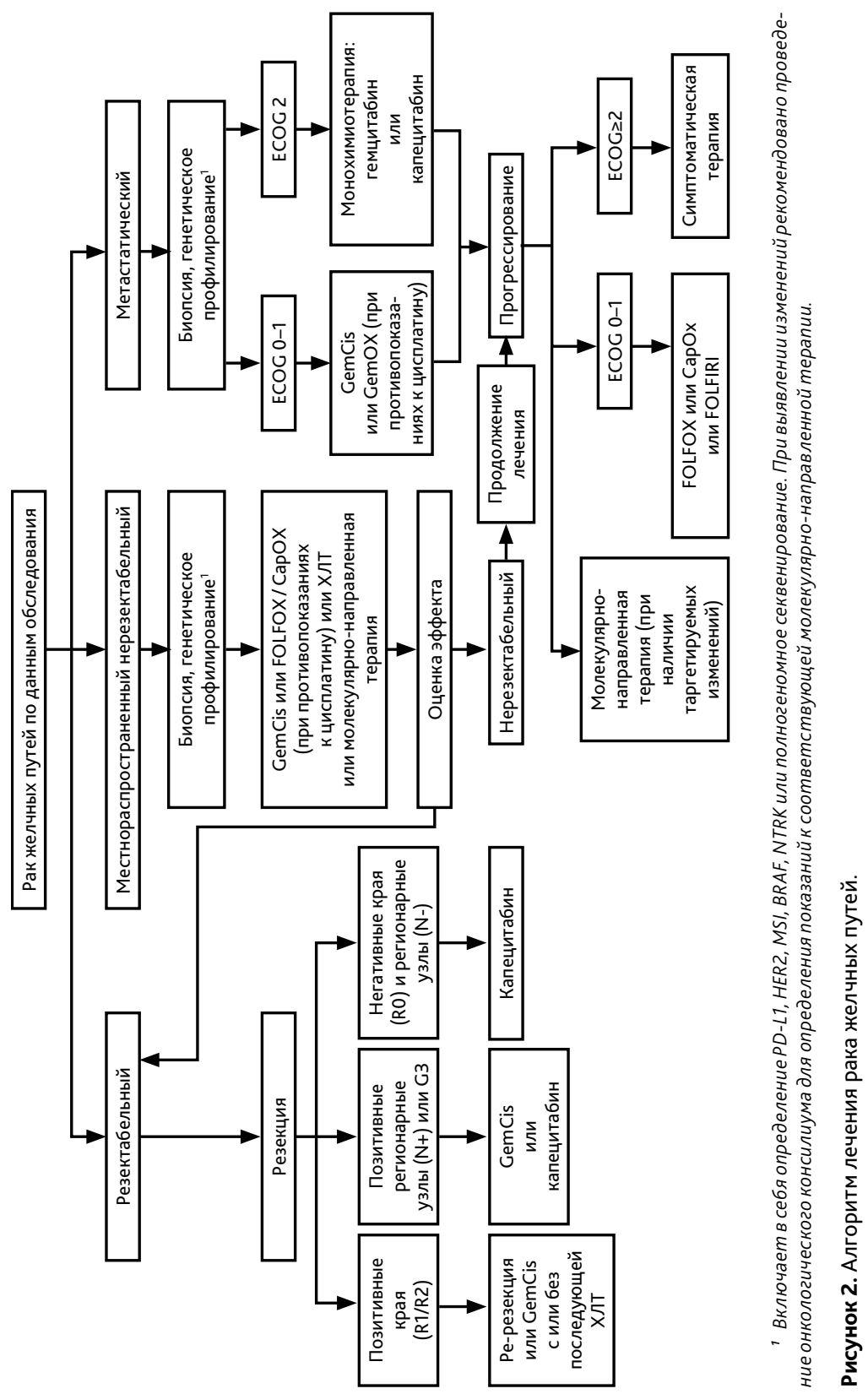

